\title{
Meta
}

Journal des traducteurs

Translators' Journal

DELABATISTA, Dirk et Lieven D'HULST (Eds.) (1993) : European

Shakespeares, Translating Shakespeare in the Romantic Age, Amsterdam-Philadelphia, John Benjamins, 256 p.

\section{Fortunato Israël}

Volume 39, numéro 3, septembre 1994

URI : https://id.erudit.org/iderudit/003232ar

DOI : https://doi.org/10.7202/003232ar

Aller au sommaire du numéro

Éditeur(s)

Les Presses de l'Université de Montréal

ISSN

0026-0452 (imprimé)

1492-1421 (numérique)

Découvrir la revue

Citer ce compte rendu

Israël, F. (1994). Compte rendu de [DELABATISTA, Dirk et Lieven D'HULST

(Eds.) (1993) : European Shakespeares, Translating Shakespeare in the Romantic

Age, Amsterdam-Philadelphia, John Benjamins, 256 p.] Meta, 39(3), 490-491.

https://doi.org/10.7202/003232ar d'utilisation que vous pouvez consulter en ligne.

https://apropos.erudit.org/fr/usagers/politique-dutilisation/ 
DELABATISTA, Dirk et Lieven D'HULST (Eds.) (1993): European Shakespeares, Translating Shakespeare in the Romantic Age, Amsterdam-Philadelphia, John Benjamins, $256 \mathrm{p}$.

La fortune de Shakespeare à l'étranger au cours des siècles constitue depuis toujours, pour les études comparatistes, un thème de prédilection. Cependant, les actes du colloque 
d'Anvers (19-21 avril 1990) ne tombent pas dans le piège du déjà dit et, sur un sujet qui semble rebattu, ouvrent de nouvelles et fascinantes perspectives. À noter, tout d'abord, l'ampleur de la confrontation où sont impliqués pour la première fois, outre la France et l'Allemagne, des pays tels que le Portugal, l'Italie, la Russie, la Pologne, la Hongrie ou les Pays-Bas avec, pour résultat, un état vraiment européen de la question, riche en ramifications et en diversité. Jamais le formidable rôle de catalyseur qu'a joué Shakespeare dans l'avènement ou l'évolution des cultures nationales sous le romantisme n'a été plus manifeste ni l'influence de la traduction plus déterminante. Autre trait digne d'attention: s'appuyant sur la théorie polysystémique d'Even Zohar, la plupart des communications et les remarquables synthèses qui clôturent chaque ensemble mesurent les traductions de la période non plus à l'aune de l'original, c'est-à-dire en termes de comparaison et d'écart, mais en tenant compte des conditions de réception et de leur intégration ou non-intégration au système d'arrivée. Il ne s'agit donc plus de jeter sur ces textes un regard normatif, de déceler gains et pertes, mais d'élargir, au travers de leur fonctionnement, la connaissance de la culture d'accueil, tant il est vrai qu'une traduction participe de tout un réseau de relations exogènes qui modifie inévitablement le profil du texte de départ. Enfin, de ce débat se dégage une définition de la traduction dramatique qui s'impose comme un genre à part soumis aux lois et aux contraintes d'un ensemble plus vaste, la représentation théâtrale. La lecture de cet ouvrage montre plus que jamais que le temps où la seule analyse linguistique et contrastive semblait suffire aux besoins du traducteur et du critique est bien révolu. 